\title{
ARYLATION OF $\beta, \gamma$-UNSATURATED LACTONES BY A HECK-MATSUDA REACTION: AN UNEXPECTED ROUTE TO ARYLDIAZENE BUTENOLIDES AND PYRIDAZINONES\#
}

\author{
Jason G. Taylor and Carlos Roque D. Correia* \\ Instituto de Quimica, Universidade Estadual de Campinas, CP 6154, 13084-971 Campinas - SP, Brasil
}

Recebido em 15/6/10; aceito em 6/8/10; publicado na web em 18/10/10

\begin{abstract}
The palladium catalysed coupling of aryldiazonium salts with $\beta$ - $\gamma$-unsaturated lactones under basic conditions has been investigated. Both $(3 H)$-furanone and $\alpha$-angelicalactone were evaluated as substrates in the Heck Matsuda reaction but both failed to afford the desired arylated butenolides. Under basic conditions, $\beta$ - $\gamma$-unsaturated lactones generate highly nucleophilic enolates that preferentially undergo azo coupling reactions with arenediazonium salts to afford aryldiazene butenolides. The electronic and steric effect of the substituents on the aryldiazonium salt in the azo coupling reaction is described. Aryldiazene-lactone derivatives were obtained in good yields from a highly facile and straightforward procedure. An aminoisomaleimide was formed from $(3 H)$-furanone and cyclised to the corresponding pyridazinones in modest yield.
\end{abstract}

Keywords: butenolides; azo coupling; Heck-Matsuda.

\section{INTRODUCTION}

Palladium-catalysed reactions are powerful synthetic tools in modern organic chemistry. ${ }^{1}$ In particular, Heck arylation of olefins have become routinely employed for convergent assembly of complex molecules. ${ }^{2}$ Over the last decade, our group ${ }^{3}$ and others ${ }^{4}$ have pursued the use of arenediazonium salts as an alternative to aryl halides and triflates. The first preliminary study exploring the reaction scope was reported by Matsuda in $1977^{5}$ and as a result, the reaction is commonly referred to as the Heck-Matsuda reaction. However, since this publication, the aromatic component in Heck coupling reactions have mostly remained limited to aryl halides and triflates and this has motivated us to expand the scope of the Heck-Matsuda reaction. The use of arenediazonium salts presents some advantages over traditional aryl halide electrophiles, ${ }^{6}$ for example, the use of phosphines as ligand are not required and thus negating the requirement for aerobic conditions, which makes the reaction more practical and easier to handle. Additionally, the reaction can be performed with or without a base and is often faster than traditional Heck protocols. ${ }^{7}$ Our attention was drawn to the work of Hyde and Buchwald ${ }^{8}$ in which it was disclosed that $\beta, \gamma$-unsaturated lactones such as $\alpha$-angelicalactone could be selectivity coupled with aryl halides at the $\gamma$-position (Scheme 1). Although a typical Heck procedure employing $\mathrm{Pd}(\mathrm{OAc})_{2}$ and a monodentate phosphine as catalyst was employed, an unusual combination of toluene and $t$-amyl alcohol as solvent was critical to the success of the reaction. Furthermore, elevated temperatures and overnight reactions were necessary for obtaining synthetically useful yields. Certain substrates such as $\beta$-substituted butenolides or lactones lacking a substituent at the $\gamma$-position, failed to provide any desired arylation products and were completely unreactive.

Thus, given the aforementioned advantages of arenediazonium salts over aryl halides, we pursued the development of a milder and straightforward methodology for the arylation of $\gamma$-butyrolactones employing arenediazonium salts. The main challenge facing the

*e-mail: roque@iqm.unicamp.br

\#Dedicated to Professor Hans Viertler on the occasion of his $70^{\text {th }}$ birthday and for his contributions towards the development of organic chemistry research in Brazil.

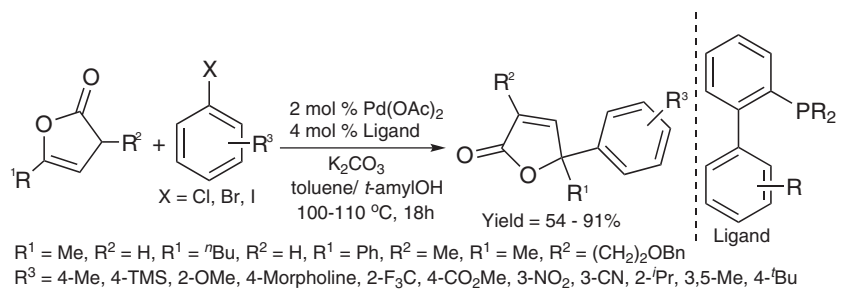

Scheme 1. Synthesis of 5,5-disubstituted butenolides by Pd-catalysed $\gamma$-arylation of $\gamma$-butyrolactones with aryl halides

Heck-Matsuda reaction is the compatibility of arenediazonoium salts with any potentially nucleophilic reagent in the reaction system. Aryldiazonium ions are well-known as potent electrophiles for azo couplings and Japp-Klingemann reactions. ${ }^{9}$ The first aryldiazene was reported in 1907 by Otto ${ }^{10}$ and in past decades, arlydiazene derivatives have often been prepared via nucleophilic addition to aryldiazonium salts. ${ }^{11}$ When carbon nucleophiles bearing an $\alpha$-hydrogen are employed, the addition product tautomerises to the hydrazone adduct (Scheme 2). ${ }^{12}$

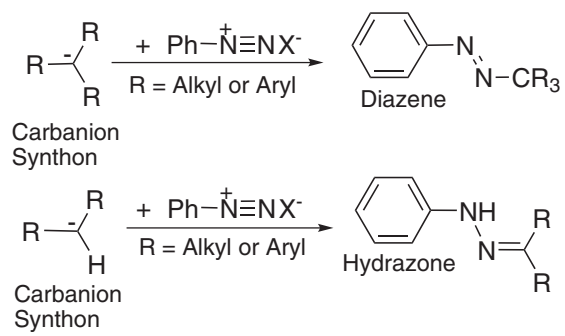

Scheme 2. Synthesis of diazenes and hydrazones from arenediazonium salts

Herein, the attempted $\gamma$-arylation of $\beta, \gamma$-unsaturated lactones by a Heck-Matsuda reaction will be presented and discussed.

\section{RESULTS AND DISCUSSION}

We speculated that 5-membered $\beta, \gamma$-lactones could react nucleophilically with arlydiazonium salts under basic conditions to afford corresponding aminoisomaleimides. ${ }^{13}$ 
To evaluate this possibility, a standard Heck-Matsuda protocol that uses base to regenerate $\operatorname{Pd}(0)$ was tested for the arylation of the $\beta, \gamma$-lactone $(3 H)$-furanone 1 (prepared according to the literature procedure).${ }^{14}$ Also an important control reaction in the absence of $\mathrm{Pd}_{2}(\mathrm{dba})_{3}$ was carried out for comparison (Scheme 3 ).

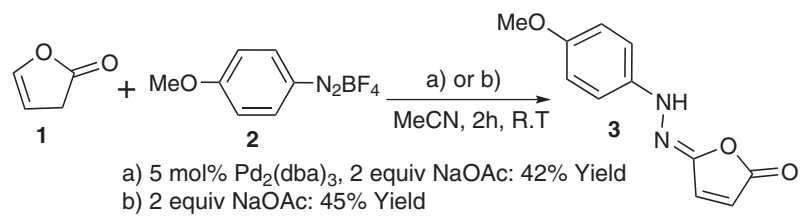

Scheme 3. Azo coupling of arenediazonium salt to $(3 H)$-furanone

Unfortunately, compound $\mathbf{1}$ underwent azo coupling with arenediazonium salt 2 in the presence and absence of $5 \mathrm{~mol}_{2} \operatorname{Pd}_{2}(\mathrm{dba})_{3}$ when using acetonitrile as solvent and sodium acetate as base, furnishing hydrazone 3 as an orange solid in 42 and $45 \%$ yield respectively. The modest yield was attributed to competitive polymerization of the olefin, which was apparent from the observed formation of a dark viscous oil in the reaction flask. ${ }^{15}$ Formation of $\mathbf{3}$ was distinguished from the Heck-adduct by the appearance of a singlet resonance at $8.23 \mathrm{ppm}$ in the ${ }^{1} \mathrm{H}$ NMR that could only be attributed to the $\mathrm{NH}$ hydrogen characteristic of a hydrazone. Aminoisomalaimide $\mathbf{3}$ has been reported to rearrange to pyridazinone $\mathbf{4}$ in refluxing acetic acid and gratifyingly this procedure gave the cyclised product in almost identical yield to that previously reported by Parnarouskis and $\mathrm{Ru}-$ binstein (Scheme 4). ${ }^{16}$

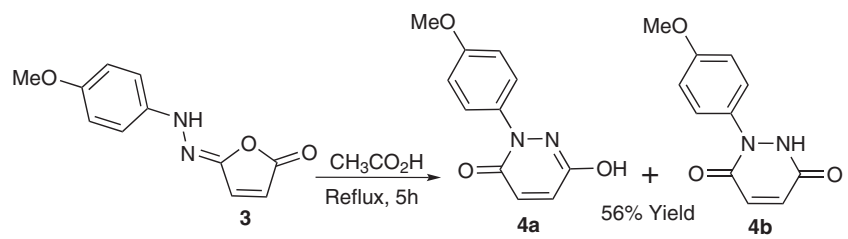

Scheme 4. Rearrangement of hydrazone to pyridazinone

The product was observed as a 3:1 mixture of tautomers $4 \mathbf{a}$ and 4b by proton NMR. Pyridazinones of this type can be prepared in one-step from maleic anhydride and the corresponding arylhydrazine in refluxing hydrochloric or acetic acid solutions. ${ }^{17}$ In contrast to the Brønsted acid mediated dehydration of arylhydrazines with maleic anhydride (Scheme 5), ${ }^{18}$ we have shown that aminoisomaleimides can also be prepared under mild basic conditions from $\beta, \gamma$-unsaturated lactones.

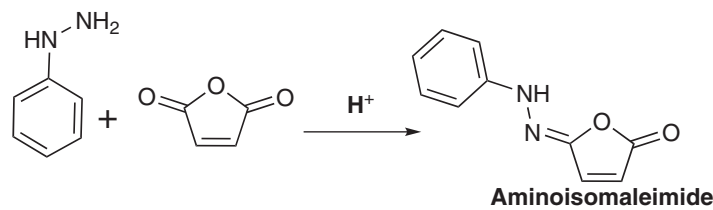

Scheme 5. Synthesis of aminoisomaleimides from arylhydrazine and maleic anhydride

An historical aminomalemide-aminoisomaleimide mischaracterisation was discussed by Conley and Wilson in 2005. Their conclusion implies that aminoisomaleimides maybe more prevalent in the literature than previously realised. ${ }^{18}$ Aminoisomaleimides are therefore intermediates in the formation of functionalised pyridazinone heterocycles that are formed from the reaction of arylhydrazines with maleic anhydride. ${ }^{19}$ Pyridazinones derivatives are attractive target molecules because of their biological activities and ease of function- alisation at various ring positions. ${ }^{20}$ However, in light of the fact that pyridazinones can be prepared in one-step from arylhydrazines, azo couplings to substrate $\mathbf{1}$ were abandoned, and instead attention was focused on commercially available $\alpha$-angelicalactone 5 . In this case, the product of the azo coupling does not bear a $\alpha$-hydrogen and as a consequence, the corresponding diazene would be formed. The Pd-catalysed arylation and azo coupling to $\alpha$-angelicalactone was examined by comparing two reactions with and without $\mathrm{Pd}_{2}(\mathrm{dba})_{3}$ (Scheme 6).

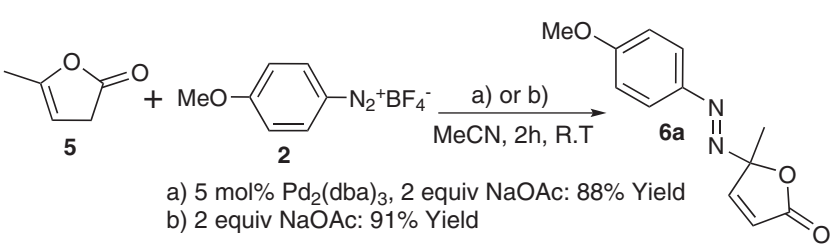

Scheme 6. Azo coupling of an arenedizonium salt to $\alpha$-angelicalactone

Once again, it was not possible to effect the arylation of a $\gamma$-butyrolactones under catalytic conditions and diazene $\mathbf{6 a}$ was formed exclusively in both cases. At first glance of the ${ }^{1} \mathrm{H}$ NMR, it appeared that the $\gamma$-aryl butenolide had been formed as all the spin-spin coupling patterns are identical to those for the aryldiazene butenolide 6a. However, on careful inspection of the ${ }^{13} \mathrm{C}$ NMR, we noticed a discrepancy for the signal corresponding to the quaternary carbon (C-5). The observed signal had a significantly different chemical shift to the Heck-adducts reported by Hyde and Buchwald (Table 1). ${ }^{8}$ Moreover, the signal furthest downfield in the ${ }^{1} \mathrm{H}$ NMR for the Heck-adduct corresponds to the olefinic hydrogen, whereas in the case of the aryldiazene lactone, H-2 is shifted furthest downfield.

Table 1. NMR comparison of diazene $6 \mathbf{k}$ and Heck adduct $\mathbf{7}^{\mathrm{a}}$

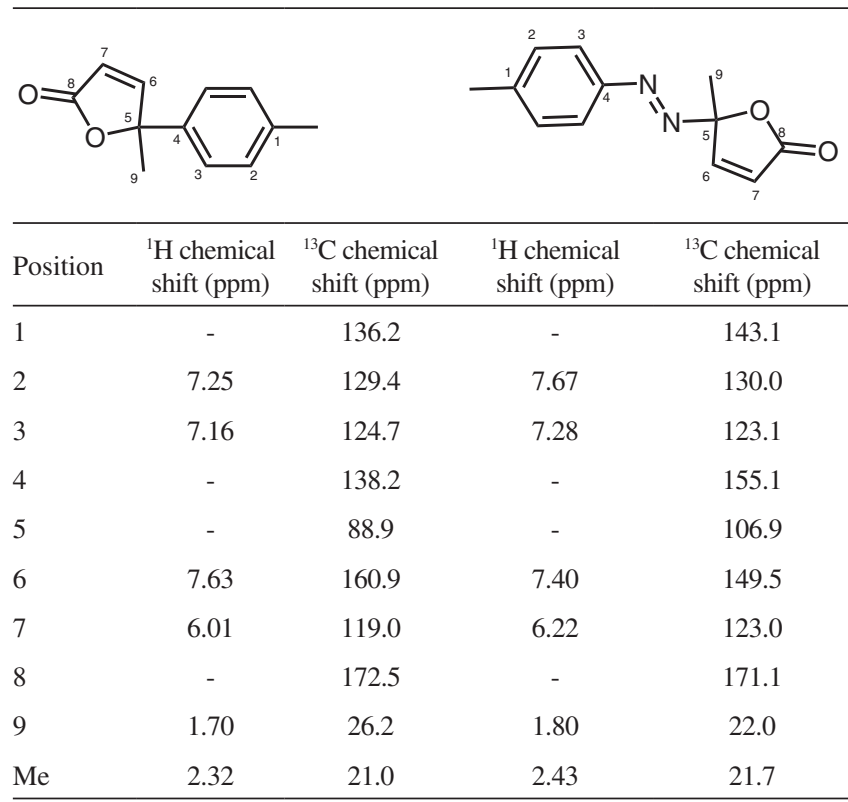

${ }^{a}$ Reaction conditions: $\alpha$-angelicalactone $(2.0 \mathrm{mmol}), \mathrm{ArN}_{2} \mathrm{BF}_{4}(4.0 \mathrm{mmol})$, $\mathrm{NaOAc}(4.0 \mathrm{mmol})$, acetonitrile, room temperature, $2 \mathrm{~h}$.

It should be mentioned that when methanol is used as a solvent in the Heck-Matsuda reaction the base could often be omitted. ${ }^{3 \mathrm{c}}$ This option was considered as a solution to circumventing the azo coupling reaction. Unfortunately, the lactone was found to be incompatible with alcoholic solvents and instead afforded the acyclic ketoester. ${ }^{21}$

Given the fact that these diazene lactones are novel compounds, the scope of the reaction was subsequently examined by introducing 
Table 2. Reactions between $\alpha$-angelicalactone and aryldiazonium salts ${ }^{\mathrm{a}}$

\begin{tabular}{lcccc}
\hline & & & \\
\hline & $4-\mathrm{OMe}$ & $\mathbf{6 a}$ & Orange & 90 \\
2 & $2-\mathrm{OMe}$ & $\mathbf{6 b}$ & Red & 84 \\
3 & $4-\mathrm{F}$ & $\mathbf{6 c}$ & Green & 92 \\
4 & $4-\mathrm{Cl}$ & $\mathbf{6 d}$ & Orange & 72 \\
5 & $4-\mathrm{Br}$ & $\mathbf{6 e}$ & Yellow & 57 \\
6 & $4-\mathrm{I}$ & $\mathbf{6 f}$ & Orange & 58 \\
7 & $4-\mathrm{OH}{ }^{\mathrm{c}}$ & $\mathbf{6 g}$ & Yellow & 80 \\
8 & $4-\mathrm{CN}$ & $\mathbf{6 h}$ & Orange & 51 \\
9 & $3-\mathrm{NO} \mathrm{C}_{2}$ & $\mathbf{6 i}$ & Red & 80 \\
10 & $4-\mathrm{Ph}$ & $\mathbf{6 j}$ & Yellow & 67 \\
11 & $4-\mathrm{Me}$ & $\mathbf{6 k}$ & Red & 53 \\
12 & $3,4-\mathrm{Cl}$ & $\mathbf{6 l}$ & Green & 42 \\
\hline
\end{tabular}

${ }^{a}$ Reaction conditions: $\alpha$-angelicalactone $(2.0 \mathrm{mmol}), \mathrm{ArN}_{2} \mathrm{BF}_{4}(4.0 \mathrm{mmol})$, $\mathrm{NaOAc}(4.0 \mathrm{mmol})$, acetonitrile, room temperature, $2 \mathrm{~h} .{ }^{\mathrm{b}}$ Isolated yield (based on lactone) after purification by column chromatography, duplicated to within $\pm 6 \%$. ${ }^{\mathrm{c}}$ In this example the counter ion of the diazonium salt was $\mathrm{CF}_{3} \mathrm{CO}_{2}$.

electronically different substituents on to the aryldiazonium salt (Table 2).

Using 2 equivalents of sodium acetate, the azo coupling proceeded smoothly to afford aryldiazene butenolides in moderate to excellent yields in most cases (entries 1 to 12). Generally, the reaction was relatively insensitive to the electronic structure of the aromatic ring as demonstrated by the high yields obtained with electron rich and poor aryldiazonium salts (entries 1-3, entries 7 and 9). In the two cases in which the diazonium salt possessed electronically neutral substituents, only modest yields were realised (entries 10 and 11). Although the 4-chloro diazonium salt was efficiently coupled to the olefin, a dramatic decrease in yield was observed when a second chloro atom was introduced in to the meta-position of the aromatic ring (entries 4 and 12). In comparison to 4-fluoro and 4-chloro substituted aryldiazonium salts (entries 3 and 4), the azo coupling was somewhat slower for the 4-bromo and 4-iodo analogues (entries 5 and 6). Finally, only a modest yield was obtained for the 4-cyano aryldiazonium salt (entry 8). Complete consumption of the olefin was observed in those cases where only modest yields were obtained from less reactive aryldiazonium salts. Once again, we suspect that competitive polymerisation of the olefin is occurring and this has been shown to occur in the presence of a mild base (for example $\mathrm{K}_{2} \mathrm{CO}_{3}$ ). ${ }^{22}$

Finally, we would like to draw attention to the variety of coloured compounds that were obtained and exclusively influenced by the substituent on the aromatic ring. Aromatic diazo compounds have been known for many decades to give a variety of colours and their application as dyes in the textile industry is well documented. ${ }^{23}$

From a mechanistic standpoint, the azo coupling is straightforward and easy to rationalise (Scheme 7).

The first step would involve abstraction of the $\alpha$ proton of $\mathbf{I}$ by an acetate anion to give a sodium enolate salt III that could undergo direct addition to the electrophilic diazo-nitrogen of II. The product IV being a $\gamma, \gamma$-disubstituted $\alpha, \beta$-unsaturated lactone is formed along with acetic acid and sodium tetrafluroborate. Interestingly, trace

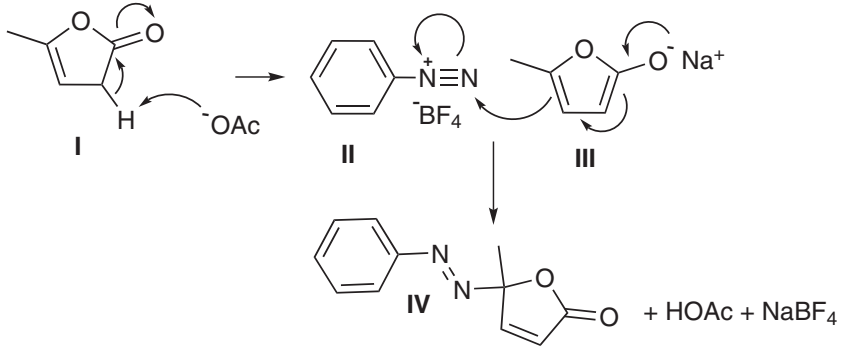

Scheme 7. Proposed mechanism

amounts of aryldiazene lactones were observed by GC-MS analysis of a reaction performed in the absence of base albeit very slowly (reactants left to react overnight in $\mathrm{MeCN}$ at room temperature). This observation emphasises the acidic nature of the $\alpha$ proton and supports our assertion that olefins of this type which generate highly nucleophilic reagents will be susceptible to azo coupling with arenediazonium salts.

\section{CONCLUSION}

In conclusion, a variety of novel aryldiazene butenolides were prepared in good yields by a base induced azo coupling of arenediazonium salts with $\beta, \gamma$-unsaturated lactones. This reaction was shown to be highly facile and rendered the arenediazonium salt unable to react in the Pd-catalysed Heck-Matssuda reaction. Although over the past ten years arenediazonoium salts have been proven to be excellent arylating reagents for a variety of olefins, they are not suitable arylating reagents for $\beta, \gamma$-unsaturated lactones. Arenediazonium salts are highly susceptible to nucleophilic addition and careful attention should be paid to this potential side reaction when considering their investigation. When evaluating a palladium catalysed Heck-Matsuda reaction, provision should always be made for a control reaction to establish if azo coupling has occurred. Nevertheless, the Heck-Matsuda reaction continues to be an excellent alternative to traditional Heck protocols for a vast array of substrates and to this end; we continue to pursue its application in the synthesis of many challenging targets.

\section{EXPERIMENTAL}

\section{General}

All commercial reagents including acetonitrile (HPLC grade), anilines, $\alpha$-angelicalactone, and sodium acetate were used as received. All aryldiazonium salts are known and prepaed according to literature procedures. After preparation, all arenediazonium tetrafluoroborates were stored in amber bottles covered with aluminum paper and stored in the fridge to avoid decomposition by light and temperature, respectively. Column chromatography was performed using silica gel 200-400 Mesh. TLC analysis were performed using silica gel plates, and vanillin solution for visualisation. ${ }^{1} \mathrm{H}$ and ${ }^{13} \mathrm{C}$ NMR spectra were acquired on Bruker spectrometers. The chemical shifts are reported in $\delta(\mathrm{ppm})$ referenced to residual protons and ${ }^{13} \mathrm{C}$ signals in deuterated chloroform. The coupling constants $(J)$ are expressed in Hertz (Hz). Full assignment of resonance signals was aided by relevant 2D NMR experiments: COSY, NOESY and HMQC. IR spectra were recorded on a Bomem FTIR MB- series B-100 model; the samples were prepared as either a liquid film between $\mathrm{NaCl}$ plates, or pressed in to $\mathrm{KBr}$ discs. Gas chromatography analysis were performed on a Hewlett Packard HP-3398A. Melting points are uncorreted. HRMS analysis were performed on a LQT FT-Ultra (ThermoScientific, Germany) spectrometer. 


\section{General procedure for preparation of aryldiazene lactones}

In a one necked round bottom flask ( $25 \mathrm{~mL})$ equipped with magntic stir bar was charged in the following order; acetonitrile ( 5 $\mathrm{mL}), \alpha$-angelicalactone $(2.0 \mathrm{mmol})$, the requisite arenediazonium salt $(4.0 \mathrm{mmol})$ and sodium acetate $(4.0 \mathrm{mmol})$ at room temperature. The reaction was allowed to stir for $2 \mathrm{~h}$ before being taken up in to water $(25 \mathrm{~mL})$ and extratced with EtOAc $(3 \times 15 \mathrm{~mL})$. The organic layers were combined, dried over sodium sulphate, volatiles removed under reduced pressure and fianally the oily residue was purifed on silica gel by column chormatography, to afford the corrsponding aryldiazene lactones.

\section{5-(2-(4-methoxyphenyl)hydrazono)furan-2(5H)-one, 3}

The product was obtained as a orange solid. mp. $148-150{ }^{\circ} \mathrm{C} ; \mathrm{R}_{\mathrm{f}}=$ 0.31 (Hexanes/ EtOAc, 6:1) after visualisation with vanillin; $\delta_{\mathrm{H}}(500$ $\left.\mathrm{MHz}, \mathrm{CDCl}_{3}\right): 8.23(1 \mathrm{H}, \mathrm{s}), 7.37(1 \mathrm{H}, \mathrm{d}, J 5.5), 7.11(2 \mathrm{H}, \mathrm{d}, J 9.0)$, $6.89\left(2 \mathrm{H}, \mathrm{d}, J\right.$ 9.0), $6.27(1 \mathrm{H}, \mathrm{d}, J 5.5), 3.81(3 \mathrm{H}, \mathrm{s}) ; \delta_{\mathrm{C}}(125 \mathrm{MHz}$, $\left.\mathrm{CDCl}_{3}\right)$ : 166.7, 154.5, 141.2, 139.6, 136.6, 128.7, 119.3, 115.1, 114.8, 55.9; $v_{\max }$ (thin film, $\left.\mathrm{cm}^{-1}\right): 1776(\mathrm{C}=\mathrm{O}), 1524,1229$.

Hydrazone 3 was coverted to pyridazinone 4 using the procedure as descrbed in the literature. ${ }^{16}$ 6-hydroxy-2-(4-methoxyphenyl) pyridazin-3(2H)-one, 4a and 1-(4-methoxyphenyl)-1,2-dihydropyridazine-3,6-dione, $\mathbf{4 b}$. The product was obtained as a beige solid. $\mathrm{mp}$. $238-240{ }^{\circ} \mathrm{C} ; \delta_{\mathrm{H}}\left(250 \mathrm{MHz}, \mathrm{DMSO}-d_{6}\right): 11.24(1 \mathrm{H}, \mathrm{s}), 7.42(2 \mathrm{H}, \mathrm{d}$, $J$ 9.0), 7.11 (1H, d, $J$ 9.5), 6.96-6.99 (3H, m), $3.77(3 \mathrm{H}, \mathrm{s}) ; \delta_{\mathrm{C}}(62.5$ MHz, DMSO- $\left.d_{6}\right): 158.6,158.2,153.0,134.9,134.2,127.7,127.2$, 113.9, 55.8.

\section{(E)-5-((4-methoxyphenyl)diazenyl)-5-methylfuran-2(5H)-one, $\mathbf{6} \boldsymbol{a}$}

The product was obtained as a orange oil.; $\mathrm{R}_{\mathrm{f}}=0.20$ (Hexanes/ EtOAc, 4:1) after visualisation with vanillin; $\delta_{\mathrm{H}}\left(500 \mathrm{MHz}, \mathrm{CDCl}_{3}\right)$ : $7.76(2 \mathrm{H}, \mathrm{d}, J 8.5), 7.41(1 \mathrm{H}, \mathrm{d}, J 5.5), 6.99(2 \mathrm{H}, \mathrm{d}, J 8.5), 6.22(1 \mathrm{H}$, d, J 5.5), $3.89(3 \mathrm{H}, \mathrm{s}), 1.79(3 \mathrm{H}, \mathrm{s}) ; \delta_{\mathrm{C}}\left(125 \mathrm{MHz}, \mathrm{CDCl}_{3}\right): 171.3$, $163.1,155.3,145.6,125.1,123.0,114.4,106.7,55.9,22.0 ; v_{\max }$ (thin film, $\left.\mathrm{cm}^{-1}\right): 1532(\mathrm{C}=\mathrm{O}), 1354,1169$.

\section{((E)-5-((2-methoxyphenyl)diazenyl)-5-methylfuran-2(5H)-one, $\boldsymbol{6} \boldsymbol{b}$}

The product was obtained as a red oil.; $\mathrm{R}_{\mathrm{f}}=0.10$ (Hexanes/ EtOAc, 4:1) after visualisation with vanillin; $\delta_{\mathrm{H}}\left(500 \mathrm{MHz}, \mathrm{CDCl}_{3}\right)$ : 7.44-7.48 (3H, m), 7.06 (1H, d, J 8.5), $6.94(1 \mathrm{H}, \mathrm{t}, J 8.0), 6.20(1 \mathrm{H}$, d, J 5.5), $3.98(3 \mathrm{H}, \mathrm{s}), 1.80(3 \mathrm{H}, \mathrm{s}) ; \delta_{\mathrm{C}}\left(125 \mathrm{MHz} \mathrm{CDCl}_{3}\right): 171.2$, 157.0, 155.2, 140.9, 133.8, 123.2, 120.9, 117.3, 113.2, 107.5, 56.4, 22.2; $v_{\max }$ (thin film, $\left.\mathrm{cm}^{-1}\right): 1773(\mathrm{C}=\mathrm{O}), 1487,1283,1121$.

\section{(E)-5-((4-fluorophenyl)diazenyl)-5-methylfuran-2(5H)-one, $\mathbf{6 c}$}

The product was obtained as a green oil.; $\mathrm{R}_{\mathrm{f}}=0.40$ (Hexanes/ EtOAc, 4:1) after visualisation with vanillin; $\delta_{\mathrm{H}}\left(500 \mathrm{MHz}, \mathrm{CDCl}_{3}\right)$ : 7.79-7,82 (2H, m), 7.40 (1H, d, J 5.5), $7.17(2 \mathrm{H}, \mathrm{t}, J 9.0), 6.24(1 \mathrm{H}$, $\mathrm{d}, J 5.5), 1.81(3 \mathrm{H}, \mathrm{s}) ; \delta_{\mathrm{C}}\left(125 \mathrm{MHz}, \mathrm{CDCl}_{3}\right): 171.0,166.2\left(\mathrm{~d}, J_{\mathrm{CF}}\right.$, 252.3), 154.8, $147.8\left(\mathrm{~d}, J_{\mathrm{CF}}, 3.0\right), 125.3\left(\mathrm{~d}, J_{\mathrm{CF}}, 9.3\right), 123.3,116.3(\mathrm{~d}$, $\left.J_{\mathrm{CF}}, 22.5\right), 106.8,22.0 ; v_{\max }\left(\right.$ thin film, $\left.\mathrm{cm}^{-1}\right): 1774(\mathrm{C}=\mathrm{O}), 1517,1116$.

\section{(E)-5-((4-chlorophenyl)diazenyl)-5-methylfuran-2(5H)-one, $\boldsymbol{6} \boldsymbol{d}$}

The product was obtained as a orange oil.; $\mathrm{R}_{\mathrm{f}}=0.17$ (Hexanes/ EtOAc, 4:1) after visualisation with vanillin; $\delta_{\mathrm{H}}\left(500 \mathrm{MHz}, \mathrm{CDCl}_{3}\right)$ : 7.80-7.86 (4H, m), $7.40(1 \mathrm{H}, \mathrm{d}, J 5.5), 6.27(1 \mathrm{H}, \mathrm{d}, J 5.5), 1.84(3 \mathrm{H}, \mathrm{s})$; C $\left(125 \mathrm{MHz}, \mathrm{CDCl}_{3}\right): 170.6,154.1,153.1,133.6,123.8,123.7,118.2$, 115.7, 107.1, 21.9; $v_{\text {max }}$ (thin film, $\left.\mathrm{cm}^{-1}\right): 1775(\mathrm{C}=\mathrm{O}), 1231,1116$.

\section{(E)-5-((4-bromophenyl)diazenyl)-5-methylfuran-2(5H)-one, $6 \boldsymbol{e}$}

The product was obtained as a yellow oil.; $\mathrm{R}_{\mathrm{f}}=0.35$ (Hexanes/ EtOAc, 4:1) after visualisation with vanillin; $\delta_{\mathrm{H}}\left(500 \mathrm{MHz}, \mathrm{CDCl}_{3}\right)$ :
$7.63(4 \mathrm{H}, \mathrm{s}), 7.40(1 \mathrm{H}, \mathrm{d}, J 5.5), 6.23(1 \mathrm{H}, \mathrm{d}, J 5.5), 1.80(3 \mathrm{H}, \mathrm{s}) ; \delta_{\mathrm{C}}$ $\left(125 \mathrm{MHz}, \mathrm{CDCl}_{3}\right): 170.9,154.6,150.0,132.7,127.0,124.6,123.4$, 106.9, 22.0; $v_{\text {max }}$ (thin film, $\left.\mathrm{cm}^{-1}\right): 1776(\mathrm{C}=\mathrm{O}), 1116$.

(E)-5-((4-iodophenyl)diazenyl)-5-methylfuran-2(5H)-one, 6 f

The product was obtained as a orange oil.; $\mathrm{R}_{\mathrm{f}}=0.23$ (Hexanes/ EtOAc, 4:1) after visualisation with vanillin; $\delta_{\mathrm{H}}\left(250 \mathrm{MHz}, \mathrm{CDCl}_{3}\right)$ : $7.86(2 \mathrm{H}, \mathrm{d}, J 8.5), 7.46(1 \mathrm{H}, \mathrm{d}, J 5.5), 7.37(2 \mathrm{H}, \mathrm{d}, J 8.5), 6.25(1 \mathrm{H}$, $\mathrm{d}, J 5.5), 1.79(3 \mathrm{H}, \mathrm{s}) ; \delta_{\mathrm{C}}\left(62.5 \mathrm{MHz}, \mathrm{CDCl}_{3}\right): 170.7,154.4,150.3$, 138.5, 124.4, 123.2, 106.7, 99.2, 21.7; $v_{\max }$ (thin film, $\mathrm{cm}^{-1}$ ): 1775 $(\mathrm{C}=\mathrm{O}), 1117,819$.

(E)-5-((4-hydroxyphenyl)diazenyl)-5-methylfuran-2(5H)-one, $\mathbf{6 g}$

The product was obtained as a yellow oil.; $\mathrm{R}_{\mathrm{f}}=0.40$ (Hexanes/ EtOAc, 4:1) after visualisation with vanillin; $\delta_{\mathrm{H}}\left(500 \mathrm{MHz}, \mathrm{CDCl}_{3}\right)$ : $11.25(1 \mathrm{H}, \mathrm{s}), 7.83(1 \mathrm{H}, \mathrm{dd}, J 1.57 .5), 7.44(1 \mathrm{H}, \mathrm{d}, J 5.5), 7.38(1 \mathrm{H}$, $\mathrm{t}, J 9.0), 7.05(1 \mathrm{H}, \mathrm{t}, J 9.0), 7.38(1 \mathrm{H}, \mathrm{d}, J 8.5), 6.27(1 \mathrm{H}, \mathrm{d}, J 5.5)$, $1.87(3 \mathrm{H}, \mathrm{s}) ; \delta_{\mathrm{C}}\left(125 \mathrm{MHz}, \mathrm{CDCl}_{3}\right): 170.7,154.8,152.4,136.5,134.8$, $133.4,123.5,120.3,118.7,105.3,22.2 ; v_{\max }\left(\right.$ thin film, $\left.\mathrm{cm}^{-1}\right): 3371$ (O-H), $1776(\mathrm{C}=\mathrm{O}), 1443$.

\section{(E)-4-((2-methyl-5-oxo-2,5-dihydrofuran-2 yl)diazenyl) benzonitrile, $\boldsymbol{6} \boldsymbol{h}$}

The product was obtained as a orange oil.; $\mathrm{R}_{\mathrm{f}}=0.20$ (Hexanes/ EtOAc, 4:1) after visualisation with vanillin; $\delta_{\mathrm{H}}\left(500 \mathrm{MHz}, \mathrm{CDCl}_{3}\right)$ : 7.80-7.85 (4H, m), 7.40 (1H, d, J 5.5), $6.27(1 \mathrm{H}, \mathrm{d}, J 5.5), 1.84(3 \mathrm{H}, \mathrm{s})$; $\delta_{\mathrm{C}}\left(125 \mathrm{MHz}, \mathrm{CDCl}_{3}\right): 170.6,154.1,153.1,133.6,123.8,123.6,118.2$, 115.7, 107.1, 22.0; $v_{\max }$ (thin film, $\left.\mathrm{cm}^{-1}\right): 2230,1773(\mathrm{C}=\mathrm{O}), 1117$.

\section{(E)-5-methyl-5-((3-nitrophenyl)diazenyl)furan-2(5H)-one, $\boldsymbol{6} \boldsymbol{i}$}

The product was obtained as a red semi solid.; $\mathrm{R}_{\mathrm{f}}=0.20(\mathrm{He}-$ xanes/ EtOAc, 4:1) after visualisation with vanillin; $\delta_{\mathrm{H}}(500 \mathrm{MHz}$, $\left.\mathrm{CDCl}_{3}\right): 8.61(1 \mathrm{H}, \mathrm{s}), 8.39(1 \mathrm{H}, \mathrm{d}, J 8.0), 8.11(1 \mathrm{H}, \mathrm{d}, J 8.0), 7.70$ $(1 \mathrm{H}, \mathrm{t}, J$ 8.0), $7.43(1 \mathrm{H}, \mathrm{d}, J 5.5), 6.29(1 \mathrm{H}, \mathrm{d}, J 5.5), 1.86(3 \mathrm{H}, \mathrm{s})$; $\delta_{\mathrm{C}}\left(125 \mathrm{MHz}, \mathrm{CDCl}_{3}\right): 170.6,154.0,151.6,149.2,130.5,128.7$, $126.4,123.8,118.2,106.9,22.0 ; v_{\max }\left(\right.$ thin film, $\left.\mathrm{cm}^{-1}\right): 1776(\mathrm{C}=\mathrm{O})$, $1534,1353,1119$.

\section{(E)-5-(biphenyl-4-yldiazenyl)-5-methylfuran-2(5H)-one, $6 \mathbf{j}$}

The product was obtained as a yellow solid. mp. $94-96{ }^{\circ} \mathrm{C} ; \mathrm{R}_{\mathrm{f}}=$ 0.37 (Hexanes/ EtOAc, 4:1) after visualisation with vanillin; $\delta_{\mathrm{H}}(500$ $\left.\mathrm{MHz}, \mathrm{CDCl}_{3}\right): 7.84$ (2H, d, J 8.5), 7.72 (2H, d, $J$ 9.0), 7.64 (2H, d, $J$ 7.0), 7.47-7.51 (3H, m), 7.43 (1H, d, J 5.5), 6.25 (1H, d, J 5.5), 1.84 $(3 \mathrm{H}, \mathrm{s}) ; \delta_{\mathrm{C}}\left(125 \mathrm{MHz} \mathrm{CDCl}_{3}\right): 171.0,154.9,150.4,145.2,140.0$, $129.2,128.4,128.2,127.5,123.6,123.2,107.0,22.1 ; v_{\max }$ (thin film, $\left.\mathrm{cm}^{-1}\right): 1767(\mathrm{C}=\mathrm{O}), 1115$.

\section{(E)-5-methyl-5-(p-tolyldiazenyl)furan-2(5H)-one, $\mathbf{6} \boldsymbol{k}$}

The product was obtained as a red oil.; $\mathrm{R}_{\mathrm{f}}=0.24$ (Hexanes/ EtOAc, 4:1) after visualisation with vanillin; $\delta_{\mathrm{H}}\left(500 \mathrm{MHz}, \mathrm{CDCl}_{3}\right): 7.66$ (2H, d, J 8.5), 7.40 (1H, d, J 5.5), 7.28 (2H, d, $J 8.5), 6.22$ (1H, d, $J$ 5.5), $2.43(3 \mathrm{H}, \mathrm{s}), 1.80(3 \mathrm{H}, \mathrm{s}) ; \delta_{\mathrm{C}}\left(125 \mathrm{MHz}, \mathrm{CDCl}_{3}\right)$ : 171.2, 155.1, $149.5,143.1,130.0,123.1,123.0,106.9,22.0,21.7 ; v_{\max }$ (thin film, $\left.\mathrm{cm}^{-1}\right): 1774(\mathrm{C}=\mathrm{O}), 1443,1116,820$.

\section{(E)-5-((3,4-dichlorophenyl)diazenyl)-5-methylfuran-2(5H)-one, $6 \mathbf{l}$}

The product was obtained as a green oil.; $R_{f}=0.27$ (Hexanes/ EtOAc, 4:1) after visualisation with vanillin; $\delta_{\mathrm{H}}\left(500 \mathrm{MHz}, \mathrm{CDCl}_{3}\right)$ : $7.88(1 \mathrm{H}, \mathrm{d}, J 2.5), 7.65(1 \mathrm{H}, \mathrm{d}, J 2.0), 7.64(1 \mathrm{H}, \mathrm{d}, J 2.0), 7.39(1 \mathrm{H}$, $\mathrm{d}, J 5.5), 6.25(1 \mathrm{H}, \mathrm{d}, J 5.5), 1.81(3 \mathrm{H}, \mathrm{s}) ; \delta_{\mathrm{C}}\left(125 \mathrm{MHz}, \mathrm{CDCl}_{3}\right)$ : 170.7, 154.3, 150.1, 136.6, 134.0, 131.3, 124.6, 123.6, 122.7, 106.8, 21.9; $v_{\max }\left(\right.$ thin film, $\left.\mathrm{cm}^{-1}\right): 1776(\mathrm{C}=\mathrm{O}), 1121,820$. 


\section{SUPPLEMENTARY MATERIAL}

Available at http://quimicanova.sbq.org.br, in PDF format, with free access.

\section{REFERENCES AND NOTES}

1. Tsuji, J.; Palladium Reagents and Catalysts: Innovations in Organic Synthesis, $1^{\text {st }}$ ed., Wiley: London, 1997.

2. For reviews see: Shibasaki, M.; Vogl, E. M.; Ohshima, T.; Adv. Synth. Catal. 2004, 346, 1533; Dounay, A. B.; Overman, L. E.; Chem. Rev. 2003, 103, 2945.

3. For selected examples see: Siqueira, F. A.; Taylor, J. G.; Correia, C. R. D.; Tetrahedron Lett. 2010, 51, 2102; Moro, A. V.; Cardoso, F. S. P.; Correia, C. R. D.; Org. Lett. 2009, 11, 3642; Pastre, J. C.; Correia, C. R. D.; Adv. Synth. Catal. 2009, 351, 1217; Machado, A. H. L.; de Sousa, M. A.; Patto, D. C. S.; Azevedo, L. F. S.; Bombonato, F. I.; Correia, C. R. D.; Tetrahedron Lett. 2009, 50, 1222; Moro, A. V.; Cardoso, F. S. P.; Correia, C. R. D.; Tetrahedron Lett. 2008, 49, 5668.

4. For selected examples see: Coy, E. D.; Jovanovic, L.; Sefkow, M.; Org. Lett. 2010, 12, 1976; Cacchi, S.; Fabrizi, G.; Goggiamani, A.; Sferrazza, A.; Synlett 2009, 8, 1277; Bartoli, G.; Cacchi, S.; Fabrizi, G.; Goggiamani, A.; Synlett 2008, 16, 2508; Barbero, M.; Cadamuro, S.; Dughera, S.; Synthesis 2006, 20, 3443.

5. Kikukawa, K.; Matsuda, T.; Chem. Lett. 1977, 159.

6. Sengupta, S.; Bhattacharyya, S.; Tetrahedron Lett. 2001, 42, 2035.

7. Kikukawa, K.; Nagira, K.; Wada, F.; Matsuda, T.; Tetrahedron 1981, 37, 31; Kikukawa, K.; Matsuda, T. Chem. Lett. 1977, 159.

8. Hyde, A. M.; Buchwald, S. L.; Org. Lett. 2009, 11, 2663.

9. Szele, I.; Zollinger, H.; Top. Curr. Chem. 1983, 112, 1.

10. Otto, D.; Berichte der Deutschen Chemischen Gesellschaft 1907, 40, 2404.

11. For examples see: Shapiro, D.; Segal, H.; Flowers, H. M.; J. Am. Chem. 1958, 80, 1194; Venturello, C.; D’Aloisio, R.; Synthesis 1979, 4, 283; Garst, M. E.; Lukton, D.; Synth. Commun. 1980, 10, 155; Blank, O.; Wetzel, A.; Ullrich, D.; Heinrich, M. R.; Eur. J. Org. Chem. 2008, 18, 3179.
12. For examples see: Jackson, A.; Joule, J. A.; Chem Commun. 1967, 9 , 459; Shawali, A. S.; Abd El-Galil, M.; Tetrahedron 1971, 27, 4305; Bestmann, H. J.; Schmid, G.; Sandmeier, D.; Tetrahedron Lett. 1980, 21, 2939; Atlan, V.; Kaim, L.; Supiot, C.; Chem Commun. 2000, 15, 1385.

13. The first aminoisomaleimide synthesis was reported in 1955 by Tsou and formed by intramolecular condensation of an $\mathrm{N}$-substituted maleamic acid using trifluroacetic anhydride as dehydrating agent: Tsou, K. C.; Barnett, R. J.; Seligman, A. M.; J. Am. Chem. Soc. 1955, 77, 4613.

14. Naesman, J. A. H.; Pensar, K. G.; Synthesis 1985, 8, 786.

15. Dimerisation and polymerisation of butenolides has been previously reported: Kraus, G. A.; Roth, B.; Tetrahedron Lett. 1977, 18, 3129.

16. Parnarouskis, M.; Rubinstein, H.; J. Heterocycl. Chem. 1976, 13, 423.

17. Meier, K. D.; Ringier, B. H.; Druey, J.; Helv. Chim. Acta 1954, 37, 523; Seymour, D.; J. Chem. Soc. 1955, 852; Baloniak, S.; Mroczkiewicz, A.; Katrusiak, A.; Pol. J. Chem. 1996, 70, 1274; Tartar, A; Melnyk, P.; Tetrahedron Lett. 1996, 37, 4145.

18. Conley, N. R.; Hung, R. J.; Willson, C. G.; J. Org. Chem. 2005, 70, 4553.

19. Johnston, A. K.; Allcock, R. W.; Jiang, Z.; Collier, I. D.; Blakli, H.; Rosair, G. M.; Bailey, P. D.; Morgan, K. M.; Kohno, Y.; Adams, D. R.; Org. Biomol. Chem. 2008, 6, 175; Natarajan, S. R.; Heller, S. T.; Nam, K.; Singh, S. B.; Scapin, G.; Patel, S.; Thompson, J. E.; Fitzgerald, C. E.; O'Keefe, S. J.; Bioorg. Med. Chem. Lett. 2006, 16, 5809.

20. Dal Piaz, P.; Vergelli, C.; Castellana, M. C.; Gioavannoni, M. P.; Pieretti, S.; J. Heterocycl. Chem. 2002, 39, 523; Matyus, P.; J. Heterocycl. Chem. 1998, 35, 1075.

21. This reaction is known to occur under basic conditions: Jones, J. B.; Barker, J. N.; Can. J. Chem. 1970, 48, 1574.

22. Lukes, R.; Syhora, K.; Collect. Czech. Chem. Commun. 1954, 19, 1205; David, P.; Langlois, H. W.; J. Am. Chem. Soc. 1948, 70, 2624.

23. Herbst, W; Hunger, K.; Prog. Org. Coat. 1978, 6, 105. 